\title{
Liderança universitária: uma revisão das publicações nacionais e estrangeiras sobre 0 tema
}

\section{RESUMO}

A liderança universitária é um campo de estudos bastante recente, se comparado ao histórico das pesquisas sobre liderança em geral. A literatura destaca a contradição de que os pesquisadores sobre o tema não estudam a liderança da própria instituição que os abriga. O presente artigo desenvolve uma revisão integrativa das pesquisas nacionais e estrangeiras a respeito de liderança universitária. Segundo a literatura, a gestão das Universidades é marcada pelo conflito entre duas visões contrapostas - o colegialismo e o gerencialismo (managerialism) -, e a liderança é vista como uma forma de se pôr fim a essa contradição. Destacam-se no trabalho as funções dos líderes universitários, assim como nos principais grupos de comportamentos dos líderes e dos liderados. Constatou-se que a produção científica brasileira possui a tendência de abordar a liderança como um papel da gestão universitária. Com base na revisão, verificou-se que as pesquisas em liderança universitária historicamente privilegiam o estudo da liderança distribuída, em vez de adotar abordagens verticais da liderança. Destaca-se, também, a nascente proposta da liderança híbrida. Conclui-se que as possibilidades de pesquisa futura são vastas, destacando-se a necessidade de contribuições teóricas e empíricas para o avanço da proposta da liderança híbrida, bem como a necessidade de pesquisas empíricas que descrevam como a liderança é praticada nas Instituições de Ensino Superior (IES) brasileiras.

Palavras-chave: Liderança universitária. Universidade. Líder. Liderança distribuída. Liderança híbrida.

Bruna Manuela Adriano

bruna.adriano@gmail.com Mestranda em Administração da Universidade do Vale do Itajá

Santa Catarina - Brasil

Flávio Ramos

flaviouni@univali.br 


\section{INTRODUÇÃO}

A liderança é um fenômeno que tem sido objeto de investigação científica há mais de um século. No entanto, a literatura destaca que até o presente momento não são facilmente encontrados consensos, principalmente no que tange aos seus construtos centrais (LAPIERRE, 1995).

A análise da literatura científica sobre liderança demonstra a existência de uma sucessão de abordagens que buscam definir a liderança sob diversos horizontes epistemológicos (NORTHOUSE, 2004). No entanto, pode-se identificar um núcleo que caracteriza especificamente esse fenômeno, uma trípode, composta pelo líder (ou líderes), os liderados e o objetivo comum perseguido (BENNIS, 2007).

Enquanto os estudos da liderança nas organizações em geral, em especial naquelas com finalidade lucrativa, possuem esse histórico de longa data, as pesquisas em liderança universitária somente iniciaram a partir da década de 1980, com um número bastante reduzido de pesquisadores dedicados à matéria. Bryman e Lilley (2009) ressaltam a contradição, pois muitos, senão a grande maioria, dos pesquisadores da liderança estão vinculados às Instituições de Ensino Superior (IES). Esses pesquisadores, porém, raramente prestam atenção para o estudo da liderança universitária.

O principal motivador para as pesquisas em liderança universitária foi a onda de reformas na gestão pública promovida pelas políticas neoliberalistas, visando a uma aproximação do serviço público às práticas gerenciais das empresas. Desse período, nasce a contradição entre a clássica forma de se gerenciar a Universidade, o colegialismo, com o gerencialismo (managerialism) (BLASCHKE; FROST; HATTKE, 2014).

As pesquisas na liderança universitária surgiram como uma forma de se superar a contradição entre o colegialismo e o gerencialismo, visto que os acadêmicos em geral manifestam aversão a conceitos, como autoridade e hierarquia, pautando-se a condução das Universidades em processos de influência para o alcance de objetivos de proveito comum. Viu-se na liderança uma forma de se organizar as Universidades, para que a sua gestão possa ser mais eficiente, sem que isso implique a adoção integral das práticas de gestão das empresas (DEARLOVE, 1995; DAVIES; HIDES; CASEY, 2001).

Ao se analisar a literatura brasileira a propósito do tema, constata-se que existem pesquisas sobre a liderança universitária, muito embora seu número seja bastante reduzido. Desse modo, como forma de se incentivar o desenvolvimento de pesquisas acerca do fenômeno da liderança universitária em IES brasileiras, pretende-se desenvolver neste artigo uma revisão das publicações sobre o tema.

As perguntas que nortearam esta pesquisa foram: Qual é o estado das pesquisas sobre liderança universitária? Quais são as abordagens da liderança pesquisadas pela liderança universitária? Quais são os principais constructos abordados? Qual é o estado das pesquisas a respeito do tema no Brasil?

\subsection{Objetivo geral}

Revisar a literatura sobre liderança universitária nacional e estrangeira, buscando, assim, compreender o estado da arte das pesquisas na matéria, considerando-se as principais abordagens que orientam a pesquisa em liderança universitária e, também, os principais constructos abordados.

\subsection{Objetivos específicos}

Como objetivos específicos, auxiliares ao atingimento da principal conclusão desta pesquisa, foram estabelecidos:

a) Identificar e selecionar pesquisas científicas sobre liderança universitária publicadas em periódicos indexados às bases de dados nacionais e internacionais: EBSCO, Scopus, SciElo e SPELL.

b) Analisar as publicações selecionadas, com o objetivo de conhecer as principais categorias abordadas pelos autores e também a extensão dos resultados das pesquisas.

c) Analisar as principais abordagens da liderança adotadas nas pesquisas sobre liderança universitária. 


\section{METODOLOGIA}

A revisão é uma forma de pesquisa científica que se utiliza de fontes bibliográficas ou eletrônicas para a obtenção dos resultados das pesquisas de outros autores, permitindo-se, desse modo, uma melhor compreensão do campo de estudo, além da identificação dos possíveis novos direcionamentos às pesquisas a respeito da matéria (ROTHER, 2007).

Há dois tipos básicos de revisão: a revisão narrativa e a revisão sistemática. Revisões narrativas são publicações amplas, que manifestam a interpretação e crítica pessoal do autor, sem necessariamente informar as fontes da pesquisa. As revisões sistemáticas são o contrário, utilizam-se de métodos explícitos e sistemáticos para identificar, selecionar e avaliar as publicações sobre o campo investigado (ROTHER, 2007).

Pode-se subdividir a revisão sistemática em quatro subespécies: revisão integrativa; meta-análise; revisão sistemática (em um sentido estrito); e revisão qualitativa. A meta-análise e a revisão sistemática são modalidades de revisão de estudos empíricos quantitativos, enquanto a revisão qualitativa envolve os métodos para revisão de pesquisas qualitativas. Diferentemente, a revisão integrativa permite o desenvolvimento de um estudo com um escopo muito mais amplo, integrando estudos teóricos ou empíricos, qualitativos ou quantitativos (WHITTEMORE, 2005; WHITTEMORE; KNAFL, 2005).

Assim, este trabalho constitui-se em uma revisão integrativa da literatura. Escolheu-se referido método justamente por ele consentir a análise das diversas publicações sobre liderança universitária, permitindo-se, desse modo, a compreensão do estado da arte das pesquisas sobre o tema.

Para o desenvolvimento deste estudo, adotou-se a proposta de Whittemore e Knafl (2005), composta por cinco fases: (a) identificação do problema; (b) busca da literatura, desenvolvida nas bases já referidas; (c) avaliação dos dados; (d) análise dos dados; (e) apresentação, que envolve a discussão dos trabalhos com as conclusões alcançadas pelo autor. Na próxima seção, serão apresentados os resultados da revisão da literatura.

\section{DEFINIÇÕES DOS CONCEITOS DE LÍDER, LIDERADO E DE LIDERANÇA}

Antes de adentrar na revisão das pesquisas sobre liderança universitária, nesta seção buscar-se-á definir os construtos líder, liderado e liderança adotados neste trabalho, entendidos como fundamentais para a posterior análise dos artigos revisados.

\subsection{Conceito de líder}

Atribui-se a origem das expressões líder e liderança a laed, que significa "caminho" na antiga língua anglo-saxônica. O verbo arcaico laeden significava tanto viajar, quanto "levar alguém pelas mãos" (GANGA; NAVARRETE, 2013, p. 54). Com base na origem etimológica, interpreta-se que o líder é a pessoa que mostra aos seus companheiros viajantes o caminho para seguir adiante (GANGA; NAVARRETE, 2013).

Nota-se que a etimologia da palavra líder indica uma relação de condução de pessoas rumo a um determinado destino. Da mesma forma, grande parte dos pesquisadores define o líder (o condutor) como uma pessoa dotada do poder de influência sobre os demais, os liderados (companheiros viajantes), para que todo o grupo atinja resultados de proveito comum (YUKL, 1989; GANGA; NAVARRETE, 2013).

No tocante à definição de líder, a grande controvérsia entre as diferentes abordagens da liderança é a explicação de quais fatores são determinantes na caracterização de quem é o líder, como ele exerce o seu poder, quais são os níveis em que o líder influencia os liderados ou é por estes influenciado e, também, em que medida o líder ou os liderados são os principais protagonistas dos resultados (YUKL, 1989).

Especialmente a questão acerca do mérito do líder a respeito dos resultados obtidos pelo grupo gera uma grande controvérsia entre os pesquisadores da área. Segundo Bass (2008), as organizações necessitam de líderes, pois sem eles os resultados esperados pelo grupo não seriam alcançados. Outro grupo de pesquisadores considera que o enfoque excessivo no líder resulta na sobrevalorização de um indivíduo em detrimento dos demais, que são igualmente importantes para o alcance dos resultados comuns (CREVANl; LINDGREN; PACKENDORFF, 2010; MINTZBERG, 2010). 
Bruna Manuela Adriano, Flávio Ramos

Em face dessa controvérsia, adota-se neste trabalho a proposta de Heifetz (1998), que prefere o verbo "mobilizar" para descrever a capacidade do líder de conduzir as pessoas para o alcance dos resultados de proveito comum, em vez do verbo "influenciar", comumente utilizado pelos demais pesquisadores. No entendimento do autor, a visão do líder como aquele que exerce grande influência reforça a ideia de que o conceito de poder é inseparável do conceito de líder, enquanto há abordagens da liderança que não veem a relação líder-liderado como uma relação de poder. Considera-se, assim, que o líder "mobiliza" seus liderados, conduzindo-os ao enfrentamento de seus próprios problemas, visando à obtenção dos resultados de interesse comum (HEIFETZ, 1998).

Portanto, define-se, neste trabalho, o líder como uma pessoa dotada da capacidade de mobilizar os liderados, no intuito do atingimento de resultados de proveito comum (HEIFETZ, 1998; BENNIS, 2007).

\subsection{Conceito de liderado}

Enquanto o conceito de líder acompanha as pesquisas em liderança desde os seus primórdios, pois que a liderança nasce como o estudo das características do líder (HOUSE; ADITYA, 1997), a preocupação com o estudo do liderado pode ser considerada um evento bastante tardio.

Enquanto a abordagem dos traços estudava exclusivamente o líder, grande parte das demais abordagens da liderança trabalha os liderados como um substantivo coletivo, identificando a massa de pessoas que está sujeita à influência do líder, sem qualquer individualidade. Apenas a partir das abordagens da liderança carismática e transformacional, o liderado passou a ser considerado individualmente, mas ainda como um sujeito da influência do líder (COLLINSON, 2006).

O próprio termo adotado para representar o liderado demonstra o baixo nível de consideração de sua influência nas relações de liderança. Em inglês, adota-se a expressão follower, ou seja, "seguidor", transmitindose uma ideia de o liderado ser uma pessoa caracterizada pela passividade, conformação, inferioridade, falta de atitude e de ambição (BLIGH, 2011; MINTZBERG, 2010; UHL-BIEN; PILLAI, 2007). ${ }^{1}$

Mais recentemente surgiram abordagens da liderança que buscam entender a perspectiva do liderado na relação com o líder, assim como abordagens que se propõem a estudar o fenômeno do "seguir" (followership), na busca por revisar a visão extensivamente centrada no líder, para se abordar com maior profundidade as formas de participação e a influência dos liderados no líder (BLIGH, 2011; COLLINSON, 2006). Essas novas linhas de interpretação da pessoa do liderado reforçam que líderes e liderados compõem grupos que buscam o atingimento de objetivos comuns e, desse modo, líder e liderado influenciam-se reciprocamente.

Sendo assim, este texto define o liderado como os indivíduos que compõem o grupo do líder e que por este são mobilizados para, em conjunto, buscarem o alcance dos resultados de proveito comum. Os liderados poderão ter uma participação maior ou menor no processo decisório, a depender da pessoa que lidera, assim como das pessoas que estão na posição de liderados (HEIFETZ, 1998).

\subsection{Conceito de liderança}

Como já foi destacado nas seções anteriores, durante muito tempo, a liderança foi considerada como o estudo das características do líder ou dos seus modos de comportamento. No entanto, um entendimento mais aprofundado sobre o assunto indica que a liderança é, na realidade, um processo relacional, que envolve líderes e liderados na busca por objetivos de proveito comum (NORTHOUSE, 2004; BENNIS, 2007).

Northouse (2004) destaca que definir a liderança como um processo significa reconhecer que a liderança não se restringe aos traços ou características que residem no líder, pois trata-se de um evento composto por transações entre líderes e liderados. Crevani, Lindgren e Packendorff (2010), nesse mesmo sentido, reforçam que a liderança envolve os processos, práticas e interações que ocorrem dentro de um grupo.

1 Bligh (2011) ressalta que os pesquisadores das relações dos liderados têm buscado um termo substituto para "seguidor", sem muito sucesso até o presente momento, pensando-se em termos como: participantes; contribuintes; membros; associados; ou colaboradores. Em português, a palavra "liderado" transmite um significado mais brando do que "seguidor", muito embora ainda represente uma relação de polarização entre uma pessoa que influencia (o líder) e uma pessoa que é influenciada (o liderado). 
Sob essa perspectiva, o conceito de Heifetz (1998) é bastante adequado para definir a liderança, que é vista para o autor como o processo de mobilização de pessoas, no sentido de enfrentarem os desafios e as mudanças necessárias para o alcance dos objetivos comuns. Nesse conceito, líder(es) e liderados são protagonistas do processo que busca o alcance dos resultados de proveito comum.

Percebe-se na literatura um constante debate sobre a diferença entre liderança e gestão. Isso porque tanto a liderança quanto a gestão envolvem processos interativos entre pessoas, na busca por objetivos definidos (NORTHOUSE, 2004). Yukl (1989) destaca que, no centro dessa controvérsia, poucos autores afirmam que liderança e gestão são conceitos sinônimos, a controvérsia reside principalmente em qual definição é mais ampla que a outra.

Mintzberg (2010) considera a liderança como um dos papéis do gestor, referente às relações com seus liderados. De acordo com o autor, diferenciar a liderança da gestão é um exercício muito mais teórico do que prático, pois é muito difícil nas organizações se pensar se em um determinado momento o gerente está liderando, ou está apenas gerindo. Assim, o autor aborda a liderança como um dos papéis do gestor, referente às relações pessoais com os membros do grupo.

De modo diverso, autores como Zaleznik e Kets de Vries (1981), e Bennis e Nanus (1988) relacionam a liderança com a atitude de "fazer as coisas certas", incutindo no líder um juízo de valor acerca dos objetivos que o grupo busca realizar, enquanto a gestão "faz certo as coisas", no sentido de que o gerente direciona sua equipe para o alcance dos resultados desejados pela organização.

Um importante aspecto a ser avaliado é a amplitude dos conceitos de líder e de gestor. A gestão está limitada ao contexto hierárquico da organização, os gerentes são pessoas formalmente designadas para se responsabilizarem por outras pessoas. O conceito de líder, no entanto, não está restrito às relações hierárquicas da organização, a liderança pode ocorrer tanto dentro da organização quanto fora dela (em organizações políticas e sociais), e, até mesmo nas organizações, as pessoas podem reconhecer como líder alguém que não foi formalmente designado como gestor, tratando-se do chamado líder informal (HARTLEY; BENINGTON, 2011).

Percebe-se, assim, que a liderança envolve os processos de interação (mobilização) entre líderes e liderados, com o intuito do alcance de objetivos comuns, não se tratando de um conceito restrito às organizações, muito embora seja um fenômeno bastante recorrente dentro delas. Na sequência, serão apresentados os resultados da revisão da literatura.

\section{LIDERANÇA UNIVERSITÁRIA}

Os estudos da liderança na área educacional compõem uma das importantes vertentes de pesquisa sobre a temática, em conjunto com a liderança na enfermagem e também, certamente, na administração de empresas. No entanto, grande parte dos estudos da liderança na área da educação dirige-se aos níveis escolares primário e secundário, debatendo-se com um foco muito mais dirigido ao papel dos diretores e professores como líderes (LEITHWOOD; BEGLEY; COUSINS, 2005).

Dessa maneira, os estudos sobre a liderança universitária são relativamente recentes. Ao revisar a literatura dos Estados Unidos da América, da Grã-Bretanha e da Austrália a propósito da eficácia da liderança na educação superior, Bryman (2007) surpreendeu-se ao identificar pouquíssimos trabalhos abordando a temática.

Os fatores que motivaram a liderança universitária a ser um aspecto desconsiderado pela própria academia durante muitos anos podem ser mais bem compreendidos com base na tensão entre o colegialismo e o gerencialismo nas IES, que serão apresentados na próxima seção.

\subsection{Colegialismo x gerencialismo nas universidades}

A preocupação tardia com o estudo da liderança universitária é fruto de uma mudança na forma como as universidades passaram a estruturar a sua própria organização e governança. Em muitos países, as políticas econômicas neoliberalistas, que influenciaram na redução do financiamento público, além do crescimento no número de estudantes ingressantes e também o aumento da competição e cooperação com as pesquisas desenvolvidas pela indústria são alguns dos fatores que promoveram essa mudança no modo de pensar a 
Bruna Manuela Adriano, Flávio Ramos

liderança e a gestão universitária. Desse modo, as universidades viram-se impelidas a adotar formas de gestão mais próximas com aquelas praticadas pelas empresas (BRADSHAW; FREDETTE, 2009; MIDDLEHURST; GOREHAM; WOODFIELD, 2009; BLASCHKE; FROST; HATTKE, 2014).

Blaschke, Frost e Hattke (2014) indicam uma oposição entre a tradicional estrutura colegialista adotada pelas universidades, contra o gerencialismo (managerialism) promovido pela aproximação destas com as empresas, adotando-se um enfoque muito mais individualista e hierarquizado no processo decisório.

As universidades tradicionalmente são caracterizadas pelo colegialismo, que marca a chamada "república da ciência", em que os representantes são eleitos pelo corpo de acadêmicos, como a figura de um primus inter pares, o primeiro entre os iguais (BOER;GOEDEGEBUURE, 2009). O colegialismo pode ser traduzido especialmente pelas premissas da autonomia institucional (ou autonomia da universidade); liberdade acadêmica individual, permitindo-se que cada pesquisador se dedique às suas áreas de interesse; e profissionalismo coletivo, marcado pela condução da universidade em órgãos colegiados, com baixos níveis de protagonismo individual (DEARLOVE, 1995; BLASCHKE; FROST; HATTKE, 2014).

Atualmente, as universidades vêm sendo pressionadas à adoção do gerencialismo, que se reflete no reforço da gestão individualizada, em detrimento de órgãos colegiados, e, igualmente, na competição entre pesquisadores, cursos, centros de ensino, universidades e países, transformando as instituições de ensino em "universidades empreendedoras" (DEARLOVE, 1995; BLASCHKE; FROST; HATTKE, 2014).

Segundo Dearlove (1995), a liderança é a solução para a dualidade colegialismo versus gerencialismo, pois ela proporciona o encontro das estruturas universitárias com as demandas da atualidade. Três motivos demonstram a necessidade da liderança universitária: (a) os acadêmicos em geral negam a legitimidade de gestores profissionais, preferindo que a gestão esteja sob seu controle; (b) a autoridade éfraca nas universidades, e os gestores não dispõem dos tradicionais meios de controle dos colaboradores; (c) uma gestão "mão de ferro" (heavy-handed) pode ser disfuncional para os processos criativos envolvidos na atividade acadêmica.

Assim sendo, considera-se que a liderança pode dar as respostas necessárias à academia, pois ela envolve os processos de construção de equipes, de assegurar o comprometimento das partes envolvidas e de incentivar todos os indivíduos a perseguir resultados compartilhados de longo prazo (DAVIES; HIDES; CASEY, 2001; DEARLOVE, 1995).

\subsection{As funções da liderança universitária}

Segundo a literatura, a liderança universitária é diversa nos diferentes níveis da instituição. Dessa forma, a liderança universitária envolve as seguintes perspectivas: (a) da universidade na sua totalidade, representada pelos níveis mais altos da instituição, como a Reitoria, Vice-Reitorias (ou Pró-Reitorias) e também os conselhos superiores; (b) a perspectiva intermediária, referente aos Centros de Ensino, que fazem a ligação entre a estrutura superior e o nível mais baixo da liderança universitária, e também as Coordenações de Curso; (c) por fim, a liderança exercida dentro dos Cursos universitários, que representam o nível mais básico da estrutura de liderança universitária, exercido, por exemplo, nos Departamentos de determinados grupos de disciplinas, ou ainda nos Laboratórios vinculados a determinados cursos universitários (BOER; GOEDEGEBUURE, 2009).

A principal diferença na forma como a liderança é praticada nesses distintos níveis reside nas funções exercidas pelos líderes dessas diferentes instâncias. Middlehurst e Elton (1992), e Middlehurst, Goreham e Elton (2009), nesse sentido, classificam a liderança universitária em seis funções que envolvem a liderança de uma instituição de ensino superior: a liderança educacional (ou política), acadêmica (ou profissional), administrativa (ou organizacional), a liderança intelectual, a liderança pessoal; e, ainda, a liderança coletiva.

A liderança educacional (ou ainda liderança política) ocorre externamente à organização e refere-se à contribuição aos debates sobre as políticas públicas e aos planos nacionais e internacionais na área da educação. A liderança acadêmica (ou liderança profissional) preocupa-se com as suas atividades-fim, na busca pela promoção do ensino, da pesquisa e da extensão. Já a liderança administrativa (ou organizacional) preocupa-se com o bemestar de toda a organização (MIDDLEHURST; ELTON, 1992; MIDDLEHURST; GOREHAM; ELTON, 2009).

Middlehurst, Goreham e Woodfield (2009) complementam a lista de funções da liderança universitária com a liderança intelectual, ampliando os níveis de conhecimento sobre uma determinada área; a liderança 
pessoal, baseada na credibilidade, no carisma, na expertise e em outras qualidades do líder; e, ainda, a liderança da equipe, desenvolvida por meio do trabalho colaborativo e das práticas de trabalho.

Boer e Goedegebuure (2009) propuseram outra forma de classificação da liderança universitária. De acordo com os autores, a liderança universitária é exercida mediante as seguintes funções: (a) liderança estratégica, incluindo a participação no estabelecimento de estratégias institucionais e também a responsabilidade pela estratégia do Centro de Ensino; (b) liderança operacional, incluindo a alocação de recursos e o suporte às funções acadêmicas; (c) liderança nos recursos humanos; (d) liderança acadêmica, incluindo o acompanhamento da docência, dos programas de pesquisa e as relações com o corpo discente; (e) liderança nas relações com stakeholders externos.

Percebe-se que há uma proximidade entre as propostas de Middlehurst e Elton, e de Middlehurst, Goreham e Woodfield (2009) com a proposta de Boer e Goedegebuure (2009). Na realidade, o último autor especifica melhor a atuação dos líderes universitários nas funções de liderança educacional e administrativa, enquanto as formas da liderança intelectual, individual e coletiva não são abordadas por Boer e Goedegebuure (2009).

Ao se analisar a liderança universitária, em seus diferentes níveis, constata-se que a liderança exercida na perspectiva da universidade envolve especialmente as funções da liderança educacional (que inclui dentro de si as relações com stakeholders externos e a liderança estratégica), e a liderança individual ou da equipe, a depender do modo como a liderança é praticada nesse nível. Sob a perspectiva das Direções de Centro e Coordenações de Curso, destaca-se a liderança educacional, entendida como liderança estratégica, assim como a liderança acadêmica e administrativa, e ainda a liderança individual ou coletiva, a depender da forma como a liderança é praticada no Centro ou no Curso. Por fim, na perspectiva mais básica, destacam-se especialmente a liderança acadêmica e a liderança intelectual. A Figura 1 representa as estruturas de liderança universitária, com base nas diferentes perspectivas de análise.

Figura 1 - A liderança universitária em suas diferentes perspectivas de análise

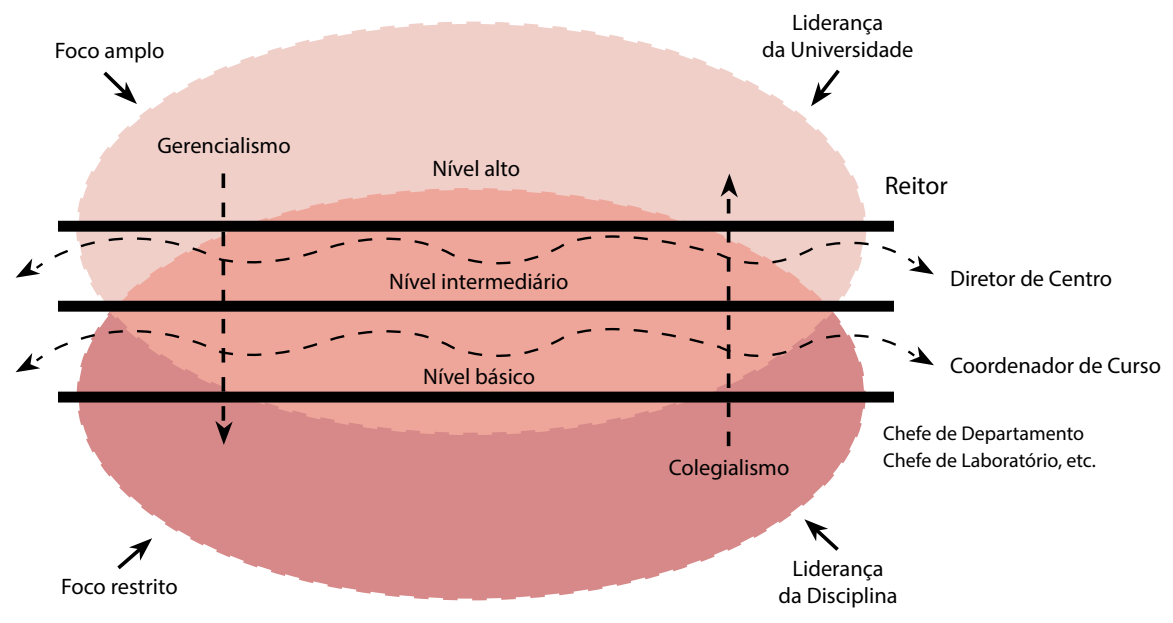

Fonte: Os autores. Baseado em Bolden, Petrov, Gosling (2008a, p. 21)

Apresentadas as principais funções da liderança universitária e as perspectivas de análise que envolvem este estudo, na próxima seção serão abordados os principais comportamentos dos líderes universitários encontrados na literatura.

\subsection{Comportamentos dos líderes e liderados universitários}

Ao revisar os principais trabalhos sobre a eficácia da liderança universitária, Bryman (2007) encontrou treze fundamentais comportamentos relacionados com os líderes universitários: (a) possuir um claro senso de direção/visão estratégica; (b) organizar o departamento para facilitar o estabelecimento da direção; (c) ser bem 
Bruna Manuela Adriano, Flávio Ramos

considerado; (d) tratar a equipe acadêmica (corpo docente e colaboradores) com justiça e integridade; (e) ser confiável e íntegro; (f) dar espaço para participação em decisões importantes/encorajar a comunicação aberta; (g) ter transparência sobre a direção da unidade acadêmica; (h) ser um modelo de conduta/ter credibilidade; (i) criar uma atmosfera positiva de trabalho; (j) atuar em favor do atingimento dos objetivos acadêmicos; (k) fornecer feedback de performance; (I) prover recursos para estimular o ensino e a pesquisa; $(\mathrm{m})$ trabalhar pela boa reputação da unidade acadêmica.

A seguir, cada um dos treze comportamentos identificados por Bryman (2007) será brevemente analisado. Destaca-se que alguns deles, por questão de pertinência temática, serão analisados conjuntamente.

\subsubsection{Visão estratégica e organização do grupo para facilitar o estabelecimento da visão}

Bryman (2007) cita diversos estudos que obtiveram como resultado a importância do líder universitário ser visionário. $\mathrm{O}$ aspecto da visão estratégica do líder considera que o líder providencia o direcionamento do grupo para os resultados que os seus liderados devem alcançar. A literatura considera que a visão envolve um conjunto de crenças a propósito de como as pessoas devem agir e interagir para atingir um estado futuro idealizado. A visão é considerada uma ideia geral e transcendente que representa os valores compartilhados do grupo, incluindo a expectativa de uma alta performance dos liderados, assim como a inspiração para que eles busquem o alcance da visão (STRANGE; MUMFORD, 2002).

O segundo comportamento identificado por Bryman (2007) aponta que os líderes universitários não somente estabelecem a visão, mas também preparam as suas organizações e os liderados, para o alcance dos objetivos comuns. Percebe-se que o segundo comportamento identificado está, na realidade, muito relacionado com a própria definição de liderança adotada neste trabalho, baseada em Heifetz (1998).

4.3.2 Ser bem considerado, confiável, íntegro e modelo de conduta e credibilidade, tratar a equipe com justiça e integridade

Bryman (2007) ressalta igualmente a importância de o líder ser bem considerado pelo grupo. Segundo o autor, as pesquisas sobre liderança universitária indicam a importância de um comportamento do líder, no sentido de preocupação com as pessoas envolvidas com a atividade universitária. Outro aspecto importante é acreditar na sua equipe e tratar seus liderados com justiça e equidade, pois ao tratá-los dessa maneira, o líder conquista a confiança de seus liderados. Como visto na seção 2.2, a compreensão mais atual do fenômeno do "seguir" (followership) entende que o liderado deve reconhecer o líder e identificar-se com ele (COLLINSON, 2006; BLIGH, 2011).

Bastante relacionado com os conceitos anteriores, além de os líderes manifestarem um tratamento honesto e íntegro com seus liderados, também é importante que os liderados percebam-no como uma pessoa confiável e íntegra (BRYMAN, 2007). Desse modo, ambos os itens podem, inclusive, ser considerados como partes de uma só concepção, visto que, se o líder tratar os seus liderados de forma justa e íntegra, estará implicitamente revelando-se para os seus liderados como uma pessoa confiável e íntegra.

Outro aspecto destacado por Bryman (2007) é que o líder universitário precisa ser um modelo de conduta para os seus liderados e, além disso, deve conquistar a confiança deles, sendo, portanto, alguém dotado de credibilidade. A credibilidade dos líderes deve ser tanto em razão do seu trabalho como acadêmicos, quanto da sua atuação como líderes. Bryman (2007) salienta, ainda, que uma das particularidades dos líderes universitários é que os liderados esperam reconhecê-los primeiro como um exemplo acadêmico, para depois admirá-los como líderes.

4.3.3 Dar espaço para participação em decisões importantes, encorajar a comunicação aberta, ser transparente quanto à direção trilhada e criar uma atmosfera positiva de trabalho

Bryman (2007) lembra que um dos aspectos mais essenciais para a liderança universitária é a oportunidade de participar das decisões importantes, assim como, de ter espaço para manifestar as suas opiniões. Percebe-se, assim, que a liderança universitária, muito embora envolva aspectos de liderança vertical, como a importância de que o líder estabeleça a visão da organização e forneça os meios para o alcance da visão, congrega, ao 
mesmo tempo, aspectos de liderança horizontal, com a importância do corpo dos liderados não somente na busca pelo atingimento dos resultados definidos pelo líder, mas também, na própria definição dos objetivos e da forma como se buscará realizá-los.

Os resultados de Bryman (2007) indicam, igualmente, que os líderes universitários devem deixar seus liderados cientes dos rumos que estão sendo tomados, promovendo, nos liderados, assim, um senso de propriedade da visão. O referido autor destaca que a criação de uma atmosfera positiva de trabalho é bastante relevante, sendo entendida como a manutenção de um clima de colegialidade entre os pesquisadores.

\subsubsection{Atuar em favor do atingimento dos objetivos acadêmicos e fornecer feeback de performance}

Por essa característica, a literatura destaca que os líderes universitários efetivamente representam os seus grupos, perante as demais instâncias universitárias e também estabelecendo relações com instituições externas. Nessa direção, Bryman (2007) destaca que os resultados das pesquisas por ele revisadas indicam que os liderados valorizam líderes universitários que efetivamente manifestam a sua preocupação com as questões do grupo, representando esses interesses diante das demais instâncias superiores universitárias, e, igualmente, com instituições externas.

Bryman (2007) salienta ainda que os líderes universitários são bem considerados pela capacidade de fornecer feedback aos seus liderados. A literatura esclarece que o feedback é um eficaz instrumento de avaliação da pessoa, permitindo, assim, quando bem oferecido, o incremento dos níveis de autoconsciência acerca de quem é o liderado e sobre como é o seu desempenho na organização (ATWATER; WALDMAN, 1998). Bryman (2007) ressalta que o meio acadêmico é marcado pela disponibilidade para a avaliação dos resultados e para o recebimento de críticas fundadas, por causa, inclusive, da característica sobre como a produção científica é avaliada. Nesse sentido, os acadêmicos têm disponibilidade para o recebimento de feedback, desde que fundado em pressupostos teóricos e práticos que demonstram os resultados positivos ou negativos de uma determinada forma de agir.

4.3.5 Prover recursos para estimular o ensino e a pesquisa, e trabalhar pela boa reputação da unidade acadêmica e do grupo.

Os líderes universitários são valorizados por obter recursos de incentivo ao desenvolvimento de pesquisas dentro do órgão que eles representam (BRYMAN, 2007). Esse tipo de conduta pode parecer muito mais um aspecto da gestão, do que da liderança universitária, no entanto, como no ambiente acadêmico esse tipo de comprometimento do líder representa uma verdadeira dedicação à unidade acadêmica, acaba-se refletindo no fortalecimento das relações de liderança.

Outro aspecto bastante semelhante é o trabalho pela boa reputação da unidade acadêmica. Esse comportamento do líder reflete-se especialmente pela formação e pela atração de pesquisadores de considerável destaque em seus campos de estudo, fortalecendo-se, desse modo, a imagem da unidade acadêmica e da Universidade (BRYMAN, 2007).

\subsubsection{Consolidação dos principais comportamentos do líder apresentados na literatura}

Como visto nas seções anteriores, muitos dos treze comportamentos identificados por Bryman (2007) são bastante próximos entre si. Dessa forma, podem-se consolidar esses comportamentos em cinco grupos, tratando-se dos seguintes: (a) estabelecimento da visão e busca pelo seu atingimento; (b) imagem do líder perante os seus liderados e dos liderados para o líder; (c) comportamento do líder em direção aos seus liderados; (d) forma de participação dos liderados nas práticas de liderança; (e) dedicação e comprometimento do líder para o atingimento dos objetivos da unidade acadêmica.

Os cinco grupos de comportamentos apresentados congregam os treze comportamentos identificados por Bryman (2007) por categorias de afinidade. Desse modo, o primeiro critério abarca tanto os aspectos do estabelecimento da visão estratégica pelo líder, quanto a organização do departamento para, assim, 
Bruna Manuela Adriano, Flávio Ramos

se estabelecer a direção. O critério da imagem do líder perante os liderados e dos liderados diante do líder envolve os aspectos do líder: ser bem considerado; ser confiável e íntegro; e também ser um modelo de conduta e credibilidade. O critério do comportamento do líder em direção aos liderados refere-se, por sua vez, ao tratamento da equipe acadêmica com justiça e integridade; à transparência; à criação de uma atmosfera de trabalho positiva; e também ao fornecimento de feedback de performance.

O critério da forma de participação dos liderados nas práticas de liderança diz respeito, particularmente, ao comportamento do líder ao dar espaço para que os liderados participem das decisões importantes, estimulando a comunicação aberta. Finalmente, o critério da dedicação e comprometimento do líder ao atingimento dos objetivos envolve os comportamentos de atuação em favor dos objetivos acadêmicos; provimento de recursos para o estímulo ao ensino e à pesquisa; e, ainda, o trabalho pela boa reputação da unidade acadêmica.

\subsection{A literatura brasileira sobre liderança universitária}

Ao pesquisar a literatura brasileira sobre liderança universitária, foi possível constatar que a escassez de trabalhos indicada pela literatura internacional também representa a realidade nacional das pesquisas a respeito do tema. As pesquisas nas bases de dados nacionais e internacionais retratam essa realidade do baixo número de pesquisas sobre o assunto. Percebeu-se que, enquanto a gestão universitária é um assunto bastante discutido na literatura, poucos desses trabalhos refletem estudos a propósito da liderança no contexto das Universidades.

Desenvolvida uma busca na base SciElo, a pesquisa para o descritor "liderança universitária" e as variações "liderança AND universidade"; "Iíder AND universidade"; "liderança AND ensino superior"; e, ainda, "líder AND ensino superior" não retornaram nenhum resultado. Por outro lado, a busca por "gestão universitária" retornou dez resultados, dos quais os trabalhos de Ésther (2011), Garcia e Carlotto (2013) e Kanan e Zanelli (2011b) podem ser considerados como pesquisas que envolvem não somente a gestão, mas também a liderança universitária.

Por sua vez, a busca na base de dados SPELL retornou o trabalho de Rizzatti, Pereira e Amaral (2012), para os descritores "liderança E universidade", tratando-se, na realidade, de um artigo que aborda a importância da liderança para a implantação do planejamento estratégico do Hospital Universitário, da Universidade Federal de Santa Catarina (UFSC). A busca pelo descritor "líder E universidade" retornou o mesmo artigo, assim como o trabalho de Pereira, Ceccato e Melo (2007), que é uma pesquisa sobre a influência do líder no processo de criatividade dos liderados, dentro de um contexto universitário. Os demais descritores apresentados no parágrafo anterior tiveram também respostas negativas nessa base de dados.

Constata-se que a liderança universitária é um tema que acaba sendo abordado em conjunto com as pesquisas sobre a gestão universitária, em uma tendência de adoção do entendimento de Mintzberg (2010), para quem a liderança é apenas um dos papéis desenvolvidos pelo líder (ver 2.1). Nesse sentido, Kanan e Zanelli (2011b) investigaram o trabalho dos docentes-gestores nas Universidades, arrolando a liderança como uma das habilidades exigidas para o exercício da gestão. Kanan e Zanelli (2011a), por seu turno, ao investigar as características de trabalho dos coordenadores de curso, concluíram pela importância do exercício da liderança.

O trabalho de Ésther (2011) investigou as competências gerenciais dos Reitores de Universidades Federais. Segundo essa pesquisa, muitos dos entrevistados destacaram diversas competências de liderança para a atuação como Reitores, citando a liderança educacional, a liderança acadêmica e ainda a liderança organizacional (ÉSTHER, 2011).

Garcia e Carlotto (2013) avaliaram o caso da criação e implantação da USP-Leste, novo campus da Universidade de São Paulo (USP), salientando a importância da liderança durante esse processo. Na mesma linha, o trabalho de Oliveira e Lima (2013) cita a liderança como uma das competências dos gestores universitários. Marra e Melo (2003), assim como Pacheco et al. (2013), e Santos e Bronnemann (2013) destacam a liderança no desempenho das funções acadêmicas nas Universidades públicas.

No que tange a teses e dissertações, foram encontrados trabalhos que abordam diretamente a temática da liderança universitária, tratando-se da dissertação de Cañizares (2001), da tese de Silva (2011) e, ainda, da publicação de Silva e Cunha (2014). 
Cañizares (2001) estudou a atuação dos líderes formais na implementação da mudança organizacional na Universidade Federal do Rio Grande do Sul (UFRGS), concluindo que o sucesso da atuação dos líderes formais depende da capacidade de criar boas relações de trabalho com os liderados, motivando-os para que estes passem pelo processo de mudança necessário.

A tese de Silva (2011) refere-se especificamente ao fenômeno da transição de líderes universitários formais que retornaram para a docência, desenvolvendo um estudo fenomenológico com Ex-reitores e Pró-reitores de Universidades vinculadas ao sistema da Associação Catarinense das Fundações Educacionais (ACAFE). Por sua vez, o artigo de Silva e Cunha (2014) estuda a transição do professor para líder formal da Universidade, também por meio de um estudo fenomenológico.

Destaca-se que a contradição entre colegialismo e gerencialismo também é abordada pela literatura brasileira. Nesse sentido, Ésther (2011) esclarece que, durante o governo de Fernando Henrique Cardoso, orientado por uma lógica neoliberalista, as Universidades federais foram reformadas, para que tais instituições se tornassem organizações pautadas em uma gestão mais próxima das práticas da iniciativa privada. A partir do governo de Luis Inácio Lula da Silva, o caráter público das Universidades Federais foi reforçado, muito embora a cobrança por resultados tenha sido mantida.

Meyer Júnior e Meyer (2011) destacam que nas Universidades privadas, organizadas sob a forma de empresas, o conflito entre gerencialismo e colegialismo também se faz presente. Os autores concluem que a ausência de teorias próprias da liderança universitária tem motivado o tratamento da gestão das Universidades privadas de modo igual às demais espécies de empresas. Na concepção dos autores, isso representa o risco de se subutilizar recursos escassos e preciosos, sem atingir a eficácia desejada.

Percebe-se que a literatura brasileira sobre liderança universitária é bastante insipiente, tratando-se de uma temática ainda abordada atrelada à gestão universitária. Na próxima seção, serão discutidas as abordagens da liderança que orientam as pesquisas sobre liderança universitária.

\section{ABORDAGENS DA LIDERANÇA UNIVERSITÁRIA}

Diversas pesquisas acerca da liderança dentro de contextos universitários obtiveram a resposta de que liderar na academia é um processo de "pastoreio de gatos" (herding cats), no sentido da tentativa de se mobilizar um grupo de pessoas que não é facilmente conduzido por alguém (BROWN; MOSHAVI, 2002; BRYMAN; LILLEY, 2009).

Bryman e Lilley (2009) lembram que uma das razões pelas quais a liderança de professores universitários é chamada de "pastoreio de gatos" é porque os docentes em geral têm uma tendência de baixa lealdade com a Universidade. Isso porque a lealdade dos pesquisadores é manifesta, segundo os autores, na seguinte ordem decrescente, com: $\left(1^{\circ}\right)$ a sua própria disciplina; $\left(2^{\circ}\right)$ o seu campo de estudo; $\left(3^{\circ}\right)$ o seu trabalho de pesquisa; $\left(4^{\circ}\right)$ o seu próprio departamento, curso e Centro de Ensino; e (5) a Universidade.

Desse modo, diferentemente das pesquisas sobre liderança em contextos empresariais, nos quais preponderam estruturas de liderança vertical, também chamada de liderança heroica, que reforça as características e qualidades pessoais do líder que fazem dele protagonista dos processos de liderança, nas pesquisas sobre liderança universitária, destaca-se o enfoque para formas horizontais de exercício da liderança, com especial destaque para a liderança distribuída.

Nesse sentido, a abordagem da liderança distribuída é aquela mais utilizada pelos pesquisadores da liderança universitária, como forma de se resolver as tensões entre colegialismo e gerencialismo, assim como, as dificuldades em se conduzir um grupo de pessoas que não espera ser diretamente influenciada por um líder. Mais recentemente, surgiram propostas que consideram que a liderança distribuída não é suficiente para explicar a liderança universitária, sendo necessário, desse modo, o estudo da liderança em configurações híbridas (BOLDEN; PETROV; GOSLING, 2008a, 2008b).

Sendo assim, na próxima seção, será apresentada a liderança distribuída, diferenciando-a da liderança compartilhada, assim como serão apresentados os resultados de pesquisas que apontam ser a liderança universitária composta por uma configuração híbrida. 


\subsection{Liderança distribuída e liderança compartilhada}

As novas propostas de estudo da liderança indicam a necessidade de se considerar esse fenômeno, sem obrigatoriamente estar centrado na figura do líder (CREVANI; LINDGREN; PACKENDORFF, 2010). O estudo dos fenômenos da liderança trabalhada como coletividades de pessoas dirigidas para o alcance de objetivos comuns é representado especialmente por duas propostas, a liderança distribuída e a liderança compartilhada, que a seguir serão mais bem apresentadas.

Diversos autores igualam os conceitos de liderança compartilhada com a liderança distribuída, como, por exemplo, Crevani, Lindgren e Packendorff (2010). No entanto, Fitzsimons, James e Denyer (2011) indicam diferenças conceituais que demonstram que ambas as propostas não estudam exatamente o mesmo objeto, ainda que sejam formas de estudo da liderança sob uma perspectiva coletiva ou horizontal.

Fitzsimons, James e Denyer (2011) atribuem as origens da abordagem da liderança compartilhada aos estudos da liderança baseada em equipes, de onde surgiu o interesse do estudo da liderança em equipes autogeridas (self-managed teams). Desse modo, proposta da liderança compartilhada trabalha sob a perspectiva de equipes em que todos os participantes agem como líderes, compartilhando do processo decisório entre si, assim como das ações necessárias para o alcance dos objetivos perseguidos (PEARCE; MANZ; SIMS JUNIOR, 2008).

A liderança distribuída, por sua vez, tem suas origens nas pesquisas da liderança na área educacional. Para a liderança distribuída, a própria organização (a escola, Universidade, a empresa, etc.) é a unidade de análise, não a equipe. Assim, a liderança distribuída busca entender como as práticas de liderança emergem em um grupo (FITZSIMONS; JAMES; DENYER, 2011).

A liderança distribuída envolve dois aspectos: 1) leader-plus, que considera que o exercício da liderança nas organizações pode envolver múltiplas pessoas, tanto líderes formais, quanto líderes informais; 2) foco nas práticas da liderança, considerando-se assim as interações entre líderes e liderados, mediadas por uma determinada situação ou contexto (SPILLANE; ZUBERI, 2009).

Figura 2 - A liderança analisada com base nas práticas

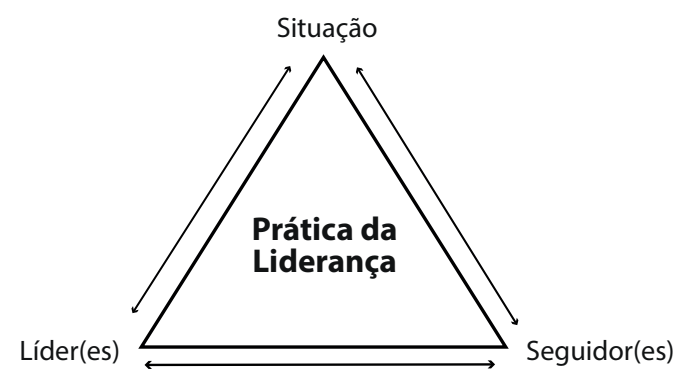

Fonte: Spillane, Halverson e Diamond (2004, p. 11)

A Figura 2 representa a proposta da liderança distribuída, que considera que as interações entre líderes e liderados, em um determinado contexto, refletem as práticas de liderança da organização. Tanto o líder quanto o liderado estão na base da figura, em uma posição de igualdade, representando-se assim que tanto o líder influi no liderado, quanto este influi no líder. Acima de ambos, está a situação, que determina como a liderança deverá ser praticada (SPILLANE; HALVERSON; DIAMOND, 2004).

Conforme Gronn (2002, 2009), a liderança distribuída pode ser vista sob dois prismas: (a) o primeiro é a simples consideração do exercício da liderança dispersa entre algumas pessoas, muitas pessoas, ou até mesmo todos os membros da organização, chamada pelo autor de liderança distribuída como ação numérica; (b) outra concepção é uma visão mais holística do fenômeno, que considera que o todo que compõe a liderança distribuída é superior à soma das relações de liderança individualmente consideradas, trabalhando-se sob a perspectiva da ação orquestrada (concertive action).

Gronn (2002) destaca, ainda, que são características da liderança distribuída a interdependência, entendida como a dependência recíproca entre dois ou mais membros da organização entre si, assim como a coordenação, que é a forma como se trabalha com as dependências dos membros nas atividades desenvolvidas pelos grupos. 
Percebe-se, assim, que liderança distribuída não é um sinônimo da liderança compartilhada, conforme considera parte da literatura. A liderança distribuída dirige seu foco de atenção às práticas da liderança que surgem nos grupos, a partir das interações entre líderes e liderados, dentro de um determinado contexto organizacional, enquanto a liderança compartilhada considera todos os membros da equipe como líderes que se autolideram, gerando um fenômeno de liderança do grupo.

\subsection{Liderança híbrida}

Uma nascente abordagem da liderança relacionada ao estudo das Universidades é a proposta da liderança híbrida, que tem por principal representante Gronn (2008, 2009, 2011). Essa proposta emerge tanto da maturidade do pensamento do referido autor, quanto de evidências empíricas.

Gronn $(2009,2011)$ considera que é mais adequado abordar a liderança como um fenômeno híbrido, do que distribuído, pois: (a) o termo híbrido é mais preciso na descrição da prática que inclui tanto os líderes individuais, quanto grupos atuando sobre formas de liderança coletiva; (b) a unidade de análise das práticas da liderança não deve ser mais a liderança distribuída, mas sim a configuração da liderança, que dentro de si poderá abarcar tanto aspectos de liderança vertical, quanto de liderança distribuída (horizontal).

Estudos empíricos sobre liderança educacional reforçam essa proposta, destacando-se Coleman (2011), no contexto da educação básica, e Bolden, Petrov e Gosling (2008a, 2008b), e Collinson e Collinson (2009), na educação superior. Tais pesquisas concluem que as práticas de liderança não são nem totalmente individualizadas nos líderes singulares, nem totalmente distribuídas no grupo, havendo configurações distintas que congregam tanto a importância de um líder forte, como a influência de toda a equipe nos processos de liderança, em outras situações.

Collinson e Collinson (2009) propõem uma liderança mista (blended leadership), já que as supostas configurações de liderança supostamente incompatíveis e dicotômicas (liderança vertical versus horizontal) são vistas na realidade como inter-relacionadas e mutuamente necessárias. Gronn (2009) sugere a adoção da expressão liderança híbrida, como forma de se contrapor à visão de que a liderança abarca um determinado tipo, que corresponde às configurações de liderança em geral. A busca pela tipicidade produz a contradição: ou a liderança é individualizada ou é distribuída, enquanto, ao se afirmar que a liderança é híbrida, não se sabe de início o quanto a liderança será individualizada ou o quanto ela será distribuída. A próxima seção apresentará um modelo de liderança híbrida para as universidades.

\subsection{Um modelo de liderança híbrida para as universidades}

Bolden, Petrov e Gosling (2008a, 2008b) desenvolveram um estudo qualitativo com 152 líderes universitários da Grã-Bretanha. Os autores concluíram que a melhor forma de se trabalhar a liderança universitária é caracterizá-la como uma forma híbrida, sendo composta por cinco diferentes dimensões: pessoal; social; estrutural; contextual; e desenvolvimental, como é possível ver na Figura 3.

Figura 3 - As dimensões da liderança na educação superior

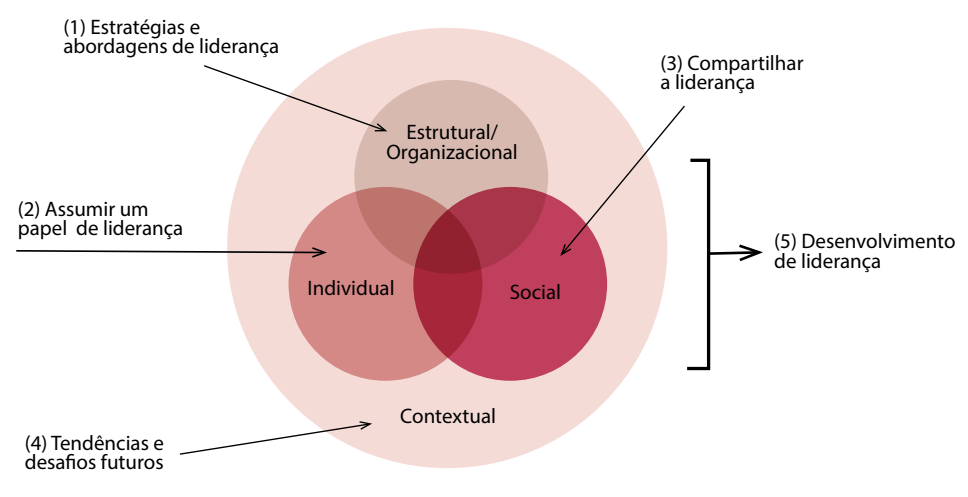

Fonte: Bolden, Petrov e Gosling (2008a, p. 6) 
Bruna Manuela Adriano, Flávio Ramos

A dimensão pessoal refere-se às qualidades pessoais, à experiência e às preferências dos líderes, com destaque à necessidade de líderes dotados de credibilidade e abertura às opiniões das demais pessoas. Dentro da dimensão social, os pesquisadores identificaram a importância das redes sociais e das relações dentro da Universidade. Essas redes representam tanto um capital social da universidade, quanto uma forma de composição de uma identidade social do grupo (BOLDEN; PETROV; GOSLING, 2008a).

A terceira dimensão, referente à estrutura, inclui os sistemas organizacionais, processos e estruturas especialmente relacionados às finanças, relações humanas, tecnologia da informação, planejamento estratégico e também ao ambiente físico. A dimensão do contexto da liderança diz respeito tanto ao contexto externo à Universidade, que inclui os ambientes social, cultural e político, quanto ao contexto interno da instituição de ensino superior, que inclui dentro de si a cultura organizacional, a história e as prioridades da organização. Destaca-se que os conflitos entre a performance econômica e a função social das universidades fazem-se presentes dentro da dimensão do contexto (BOLDEN; PETROV; GOSLING, 2008a).

Finalmente, a quinta dimensão do modelo proposto por Bolden, Petrov e Gosling (2008a, 2008b) refere-se aos aspectos desenvolvimentais da liderança universitária. Segundo os resultados encontrados pelos autores, os entrevistados relataram a importância das suas experiências de desenvolvimento pessoal para tornarem-se verdadeiros líderes (desenvolvimento de líderes), tanto quanto a busca pela promoção do desenvolvimento de liderança nas Universidades e, ainda, do desenvolvimento da própria Universidade (desenvolvimento organizacional).

Apresentados os principais resultados da revisão da literatura sobre as abordagens que orientam as pesquisas na liderança universitária, a próxima seção traz os resultados obtidos por esta pesquisa.

\section{CONCLUSÃO}

Esta pesquisa foi desenvolvida no intuito de revisar as publicações nacionais e estrangeiras sobre liderança universitária. Buscou-se, assim, analisar quais são os principais resultados obtidos até este momento, como forma de se poder contribuir, indicando as possibilidades de pesquisa futura no campo.

Constatou-se que tanto no Brasil, quanto no exterior, a liderança universitária é abordada como a solução à contradição entre o colegialismo e o gerencialismo nas IES, permitindo-se assim que as Universidades atuem de modo mais ágil e dinâmico, sem que isso implique necessariamente a transformação do seu modo de agir, para torná-lo similar, senão idêntico às práticas gerenciais das organizações privadas.

A literatura indica que a liderança universitária é exercida em diferentes funções, destacando-se as classificações de Middlehurst e Elton (1992), Middlehurst, Goreham e Woodfield (2009), e de Boer e Goedegebuure (2009), que demonstram que a liderança universitária possui distintas funções, a depender do nível de análise das instâncias universitárias.

Outra constatação desta pesquisa é que a literatura indica um grupo de comportamentos que traduzem a ação do líder universitário e também dos seus liderados. Com base nos treze comportamentos identificados por Bryman (2007), foram propostos cinco grupos de categorias que abarcam os principais comportamentos do líder e dos liderados: estabelecimento da visão e busca pelo seu atingimento; imagem do líder perante os seus liderados e dos liderados perante o líder; comportamento do líder em direção aos seus liderados; da forma de participação dos liderados nas práticas de liderança; e, ainda, dedicação e comprometimento do líder para o atingimento dos objetivos.

No tocante às pesquisas brasileiras sobre liderança universitária, constatou-se que o número de publicações é bastante reduzido, sendo a liderança comumente abordada como um dos aspectos ou papéis do gestor universitário, em uma concepção bastante aproximada da proposta de Mintzberg (2010). Os trabalhos que explicitamente estudaram a liderança universitária acabaram por se restringir à análise da influência da liderança nos processos criativos do grupo, em determinados processos de gestão, como a implementação do planejamento estratégico ou das mudanças, ou ainda, na análise da experiência de vida das pessoas que deixaram a docência para tornarem-se líderes, ou retornaram à docência após atuarem como líderes universitários.

Com relação às abordagens da liderança que orientam as pesquisas na área, com base na revisão, constatouse que, diferentemente das pesquisas sobre liderança nas empresas, nas quais preponderam estudos de liderança 
vertical, as pesquisas a respeito de liderança universitária tendem a privilegiar formas de liderança mais horizontal, valorizando-se, desse modo, abordagens que valorizam a atuação de todo o grupo nos processos de liderança, não enfatizando exclusivamente o protagonismo do líder.

Verificou-se que a abordagem da liderança distribuída exerceu grande influência nas pesquisas acerca de liderança universitária, mas que, a partir tanto do amadurecimento do pensamento de Gronn (2008, 2009, 2011), e também de evidências empíricas, atualmente propõe-se uma nova abordagem da liderança, a liderança híbrida, como o modelo que melhor traduz a liderança universitária, integrando não só certos processos de liderança um modelo mais individualizado, como um modelo mais distribuído em outros processos de liderança. Assim sendo, apresentou-se a proposta de Bolden, Petrov e Gosling (2008a, 2008b) para um modelo de liderança híbrida para as Universidades.

A partir dos resultados da revisão, conclui-se que as possibilidades de pesquisa na área são bastante vastas, demandando o desenvolvimento de estudos, tanto teóricos, como empíricos sobre o tema. A avaliação e a testagem da liderança híbrida na prática são um grande horizonte de pesquisas sobre o assunto. Outro aspecto bastante relevante, especialmente no caso brasileiro, é o estudo empírico, tanto por métodos qualitativos, quanto quantitativos, sobre a forma como a liderança é praticada nas IES brasileiras, sejam elas públicas, comunitárias ou privadas.

\title{
UNIVERSITY LEADERSHIP: A REVIEW OF NATIONAL AND INTERNATIONAL PUBLICATIONS ON THE SUBJECT
}

\begin{abstract}
University leadership is a very recent field, when compared to the history of research on leadership in general. The literature highlights the contradiction that the researchers on the subject do not study the leadership of their own institutions. This paper develops a review of national and international research on university leadership. The literature points out that the management of universities is marked by the conflict between two opposing views: collegialism and managerialism. Leadership is seen as a form ending in this conflict. It was also found that the Brazilian scientific literature on the subject has a tendency to address leadership as a role of university management. In reviewing the literature it has also been found that research on university leadership favours the study of distributed leadership instead of vertical approaches to leadership. It also showed the emerging proposal of hybrid leadership. We conclude that the possibilities for future research on the subject are vast, highlighting the need for theoretical and empirical contributions to the advancement of the proposed hybrid leadership, as well as the need for empirical studies that describe how leadership is practiced in Higher Education Institutions (HEI).
\end{abstract}

Keywords: University leadership. University. Leader. Distributed leadership. Hybrid leadership.

\section{REFERÊNCIAS}

ATWATER, L.; WALDMAN, D. 360 Degree feedback and leadership development. Leadership Quarterly, Amsterdam, v. 9, n. 4, p. 423-426, 1998. Disponível em: <http://www.scopus.com/>. Acesso em: 2 abr. 2014.

BASS, B. M. The Bass handbook of leadership: theory, research \& managerial applications. 4th ed. New York: Free Press, 2008.

BENNIS, W. The challenges of leadership in the modern world: introduction to the special Issue. American psychologist, Illinois, v. 62, n. 1, p. 2-5, 2007. Disponível em: <http://www.scopus.com>. Acesso em: 13 abr. 2014.

BENNIS, W.; NANUS, B. Líderes: estratégias para assumir a verdadeira liderança. São Paulo: Harbra, 1988.

BLASCHKE, S.; FROST, J.; HATTKE, F. Towards a micro foundation of leadership, governance, and management 
Bruna Manuela Adriano, Flávio Ramos

in universities. Higher Education, Dordrecht, Netherlands, v. 68, p. 711-732, 2014. Disponível em: <http:// download.springer.com/>. Acesso em: 17 jan. 2015.

BLIGH, M. C. Followership and follower-centred approaches. In: BRYMAN et al. The SAGE handbook of leadership. London: Thousand Oaks; New Delhi: Singapore, 2011. p. 425-436.

BOER, H.; GOEDEGEBUURE, L. The changing nature of the academic deanship. Leadership, London, UK, v. 5, n. 3, p. 347-364, 2009. Disponível em: <http://lea.sagepub.com/content/5/3/347.full.pdf>. Acesso em: 18 jan. 2015.

BOLDEN, R.; PETROV, G.; GOSLING, J. Developing collective leadership in higher education. London: Leadership Foundation for Higher Education, 2008a.

BOLDEN, R.; PETROV, G.; GOSLING, J. Tensions in higher education leadership: towards a multi-level model of leadership practice. Higher Education Quarterly, London, UK, v. 62, n. 4, p. 358-376, 2008b. Disponível em: <http://www.scopus.com>. Acesso em: 17 jan. 2015.

BRADSHAW, P.; FREDETTE, C. Academic governance of universities: reflections of a senate chair on moving from theory to practice and back. Journal of Management Inquiry, London, UK, v. 18, n. 2, p. 123-133, 2009. Disponível em: <http://jmi.sagepub.com/content/18/2/123.full.pdf>. Acesso em: 17 jan. 2015.

BROWN, F. W; MOSHAVI, D. Herding academic cats: faculty reactions to transformational and contingent reward leadership by department chairs. Journal of Leadership \& Organizational Studies, Nebraska, v. 8, n. 3, p. 79-93, Winter 2002. Disponível em: <http://search.ebscohost.com/>. Acesso em: 18 jan. 2015.

BRYMAN, A. Effective leadership in higher education: a literature review. Studies in higher education, London, UK, v. 32, n. 6, p. 693-710, 2007. Disponível em: <http://www.scopus.com>. Acesso em: 17 jan. 2015.

BRYMAN, A.; LILLEY, S. Leadership researchers on leadership in higher education. Leadership, London, UK, v. 5, n. 3, p. 331-346, 2009. Disponível em: <http://www.scopus.com/>. Acesso em: 18 jan. 2015.

CAÑIZARES, J. C. L. Análise da gestão do líder formal em relação à implementação da mudança organizacional. Estudo de caso na Universidade Federal do Rio Grande do Sul. 2001. Dissertação (Mestrado) - Universidade Federal do Rio Grande do Sul, Porto Alegre.

COLEMAN, A. Towards a blended model of leadership for school-based collaborations. Educational Management Administration \& Leadership, Nottingham, UK, v. 39, n. 3, p. 296-316, May 2011. Disponível em: <http://ema.sagepub.com/content/39/3/296.full.pdf >. Acesso em: 17 jan. 2015.

COLLINSON, D. Rethinking followership: a post-structuralist analysis of follower identities. Leadership Quarterly, Amsterdan, v. 17, n. 2, p. 179-189, 2006. Disponível em: <http://www.scopus.com>. Acesso em: 18 jan. 2015.

COLLINSON, D.; COLLINSON, M. 'Blended leadership': employee perspectives on effective leadership in the UK further education sector. Leadership, London, UK, v. 5, n. 3, p. 365-380, 2009. Disponível em: <http://lea. sagepub.com/content/5/3/365.full.pdf>. Acesso em: 17 jan. 2015.

CREVANI, L.; LINDGREN, M.; PACKENDORFF, J. Leadership, not leaders: on the study of leadership as practices and interactions. Scandinavian Journal of Management, Örebro, Sweden, v. 26, n. 1, p. 77-86, 2010. Disponível em: <http://www.scopus.com>. Acesso em: 28 jan. 2014.

DAVIES, J.; HIDES, M. T.; CASEY, S. Leadership in higher education. Total Quality Management, London, UK, v. 12, n. 7, p. 1025-1030, 2001. Disponível em: <http://www.tandfonline.com/>. Acesso em: 18 jan. 2015.

DEARLOVE, J. Collegiality, managerialism and leadership in English universities. Tertiary Education and Management, Dordrecht, Netherlands, v. 1, n. 2, p. 161-169, 1995. Disponível em: <http://www.tandfonline. com>. Acesso em: 17 jan. 2015.

ÉSTHER, A. B. As competências gerenciais dos reitores de universidades federais em Minas Gerais: a visão da 
alta administração. Cadernos EBAPE.BR, Rio de Janeiro, v. 9, p. 648-667, 2011. Disponível em: <http://www. scielo.br/>. Acesso em: 17 jan. 2015.

FITZSIMONS, D.; JAMES, K. T.; DENYER, D. Alternative approaches for studying shared and distributed leadership. International Journal of Management Reviews, Liverpool, UK, v. 13, n. 3, p. 313-328, 2011. Disponível em: <http://onlinelibrary.wiley.com/>. Acesso em: 13 nov. 2014.

GANGA, F.; NAVARRETE, E. Enfoques asociados al liderazgo eficaz para la organizació. Revista gaceta laboral, Venezuela, v. 19, n. 1, p. 52-77, 2013. Disponível em: <http://search.ebscohost.com>. Acesso em: 10 fev. 2014.

GARCIA, S. G.; CARLOTTO, M. C. Tensões e contradições do conceito de organização aplicado à universidade: o caso da criação da USP-Leste. Avaliação: revista da avaliação da educação superior, Sorocaba, v. 18, p. 657684, 2013. Disponível em: <http://www.scielo.br/>. Acesso em: 17 jan. 2015.

GRONN, P. Distributed leadership as a unit of analysis. Leadership Quarterly, Amsterdan, v. 13, n. 4, p. 423451, Aug 2002. Disponível em: <http://www.sciencedirect.com/>. Acesso em: 11 jun. 2014.

GRONN, P. The future of distributed leadership. Journal of educational administration, Brisbane, Australia, v. 46, n. 2, p. 141-158, 2008. Disponível em: <http://www.scopus.com>. Acesso em: 17 jan. 2015.

GRONN, P. Leadership configurations. Leadership, London, UK, v. 5, n. 3, p. 381-394, Aug 2009. Disponível em: <http://www.scopus.com>. Acesso em: 17 jan. 2015.

GRONN, P. Hybrid configurations of leadership. In: BRYMAN et al. The SAGE handbook of leadership. London; Thousand Oaks; New Delhi; Singapore, 2011. p. 437-454.

HARTLEY, J.; BENINGTON, J. Political leadership. In: BRYMAN et al. The SAGE handbook of leadership. London; Thousand Oaks; New Delhi; Singapore, 2011. p. 203-214.

HEIFETZ, Ronald Abadian. Leadership without easy answers. Oxford: President and Fellows of Harvard College, 1998.

HOUSE, R. J. A. ADITYA, R. N. The social scientific study of leadership: quo vadis? Journal of Management, Örebro, Sweden, v. 23, n. 3, p. 409-473, 1997. Disponível em: <http://jom.sagepub.com/content/23/3/409>. Acesso em: 11 fev. 2014.

KANAN, L. A.; ZANELLI, J. C. Características do trabalho de coordenadores de curso no contexto universitário. REP - Revista Espaço Pedagógico, Passo Fundo, v. 18, n. 1, p. 151-170, jan./jun. 2011 a. Disponível em: <http://www.upf.br/seer/index.php/rep/article/viewFile/2072/1299>. Acesso em: 17 jan. 2015.

KANAN, L. A.; ZANELLI, J. C. Envolvimento de docentes-gestores com o trabalho no contexto universitário. Psicologia \& Sociedade, Belo Horizonte, v. 23, p. 56-65, 2011b. Disponível em: <http://www.scielo.br/>. Acesso em: 17 jan. 2015.

LAPIERRE, L. Imaginário e liderança: na sociedade, no governo, nas empresas e na mídia. São Paulo: Atlas, 1995. v. 1.

LEITHWOOD, K.; BEGLEY, P. T.; COUSINS, J. B. Developing expert leadership for future schools. London: The Falmer, 2005.

MARRA, A. V.; MELO, M. C. O. L. Docente-gerente: o cotidiano de chefes de departamento e coordenadores em uma Universidade Federal. In: Encontro da ANPAD, 27., 2003, Atibaia. Anais do XXVII EnANPAD. Atibaia: ANPAD, 2003. Disponível em: <http://www.anpad.org.br/diversos/trabalhos/EnANPAD/enanpad_2003/GRT/2003_ GRT1135.pdf>. Acesso em: 17 jan. 2015.

MEYER JÚNIOR, V.; MEYER, B. “Managerialism” na gestão universitária: dilema dos gestores de instituições privadas. In: Encontro da ANPAD, 35., 2011, Rio de Janeiro. Anais do XXXV EnANPAD. Rio de Janeiro: ANPAD, 2011. Disponível em: <http://www.anpad.org.br/admin/pdf/ESO620.pdf>. Acesso em: 17 jan. 2015. 
Bruna Manuela Adriano, Flávio Ramos

MIDDLEHURST, R.; ELTON, L. Leadership and management in higher education. Studies in Higher Education, London, UK, v. 17, n. 3, p. 251-266, 1992. Disponível em: <http://search.ebscohost.com/>. Acesso em: 18 jan. 2014.

MIDDLEHURST, R.; GOREHAM, H.; WOODFIELD, S. Why research leadership in higher education? Exploring contributions from the UK's Leadership Foundation for Higher Education. Leadership, London, UK, v. 5, n. 3, p. 311-329, 2009. Disponível em: <http://lea.sagepub.com/content/5/3/311.full.pdf>. Acesso em: 18 jan. 2015.

MINTZBERG, H. Managing: desvendando o dia a dia da gestão. Porto Alegre: Bookman, 2010.

NORTHOUSE, P. G. Leadership: theory and practice. 3th ed. Thousand Oaks; London; New Dehli: Sage Publications, 2004.

OLIVEIRA, W. S.; LIMA, M. D. Competências e função gerencial: desvendando o gap (lacuna) de competências de gestores públicos no núcleo de educação de uma universidade federal brasileira. Revista de gestão universitária na América Latina - GUAL, Florianópolis, v. 6, n. 3, p. 44-60, set. 2013. Disponível em: <http:// www.redalyc.org/articulo.oa?id=319328457003>. Acesso em: 17 jan. 2015.

PACHECO, A. S. V. et al. Proposta de melhoria de desempenho nas funções administrativas em uma universidade federal. Revista gestão universitária na América Latina - GUAL, Florianópolis, v. 6, n. 1, p. 42-59, jan. 2013. Disponível em: <http://www.redalyc.org/articulo.oa?id=319327518004>. Acesso em: 17 jan. 2015.

PEARCE, C. L.; MANZ, C. C.; SIMS JUNIOR, H. P. The roles of vertical and shared leadership in the enactment of executive corruption: implications for research and practice. Leadership Quarterly, Amsterdan, v. 19, n. 3, p. 353-359, 2008. Disponível em: <http://www.scopus.com>. Acesso em: 13 nov. 2014.

PEREIRA, M. F.; CECCATO, C. M. T.; MELO, P. A. A influência do líder no processo de criatividade dos funcionários de Centros de Ensino de uma Universidade Pública Federal. RAU Revista de Administração da UNIMEP, Piracicaba, v. 5, n. 2, p. 127-148, maio/ago. 2007. Disponível em: <http://www.raunimep.com.br/ojs/index. php/regen/article/view/21>. Acesso em: 17 jan. 2015.

RIZZATTI, G.; PEREIRA, M. F.; AMARAL, H. C. M. A influência da liderança na condução do processo de implementação do planejamento estratégico: estudo do caso no Hospital Universitário da Universidade Federal de Santa Catarina. Revista Ibero-Americana de Estratégia - RIAE, São Paulo, v. 11, n. 2, p. 170-196, maio/ago. 2012. Disponível em: <http://dx.doi.org/10.5585/riae.v11i2.1879>. Acesso em: 17 jan. 2015.

ROTHER, E. T. Editorial: revisão sistemática x revisão narrativa. Acta Paulista de Enfermagem, São Paulo, v. 20, n. 2, p. v-vi, abr./jun. 2007. Disponível em: <www.redalyc.org/articulo.oa?id=307026613004>. Acesso em: 19 nov. 2014.

SANTOS, L.; BRONNEMANN, M. R. Desafios da gestão em instituições de ensino superior: um estudo de caso a partir das percepções de diretores de centro de uma IES pública do sul do Brasil. Revista Gestão Universitária na América Latina - GUAL, Florianópolis, v. 6, n. 1, p. 1-21, jan. 2013. Disponível em: <http:// www.redalyc.org/articulo.oa?id=319327518002>. Acesso em: 17 jan. 2015.

SILVA, F. M. V. A transição de líder para contribuidor individual: a experiência vivida pelo ser gestor universitário. 2011. Tese (Doutorado) - Programa de Pós-Graduação em Engenharia de Produção, Universidade Federal de Santa Catarina, Florianópolis, 2011. Disponível em: < https://repositorio.ufsc.br/ handle/123456789/95224>. Acesso em: 17 jan. 2015.

SILVA, F. M. V.; CUNHA, C. J. C. A. O relacionamento interpessoal: transições de professores universitários. Revista de Negócios, Blumenau, v. 19, n. 2, p. 62-85, 2014. Disponível em: <http://proxy.furb.br/ojs/index. php/rn/article/view/2609>. Acesso em: 17 jan. 2015.

SPILLANE, J. P.; ZUBERI, A. Designing and piloting a leadership daily practice log: using logs to study the practice of leadership. Educational Administration Quarterly, Ohio, USA, v. 45, n. 3, p. 375-423, 2009. Disponível em: <http://www.scopus.com>. Acesso em: 16 jan. 2015. 
STRANGE, J. M.; MUMFORD, M. D. The origins of vision. Charismatic versus ideological leadership. Leadership Quarterly, Amsterdan, v. 13, n. 4, p. 343-377, 2002. Disponível em: <http://www.scopus.com/>. Acesso em: 17 jan. 2015.

UHL-BIEN, M.; PILLAI, R. The romance of leadership and the social construction of followership. In: SHAMIR, R. et al. Follower-centered perspectives on leadership: a tribute to the memory of James R. Meindl. Greenwich: Information Age, 2007. p. 187-209.

WHITTEMORE, R. Combining evidence in nursing research: methods and implications. Nursing Research, New York, USA, v. 54, n. 1, p. 56-62, Jan./Feb. 2005. Disponível em: <www.scopus.com/>. Acesso em: 16 fev. 2015.

WHITTEMORE, R.; KNAFL, K. The integrative review: updated methodology. Journal of Advanced Nursing, Oxford, England, v. 52, n. 5, p. 546-553, Dec. 2005. Disponível em: <http://onlinelibrary.wiley.com>. Acesso em: 16 fev. 2015.

YUKL, G. Managerial leadership: a review of theory and research. Journal of Management, Örebro, Sweden, v. 15, n. 2, p. 251-289, 1989. Disponível em: <http://search.ebscohost.com>. Acesso em: 15 fev. 2014.

ZALEZNIK, A.; KRETS DE VRIES, M. F. R. O poder e a mente empresarial. São Paulo: Livraria Pioneira, 1981. 